\title{
A High-Pressure Shear Testing Approach to Measure Flow Stresses Near a Friction Stir Welding Tool
}

\author{
David Prymak \\ Brigham Young University, prymakdavid@byu.edu \\ Michael Miles \\ Brigham Young University, mmiles@byu.edu \\ Tracy W. Nelson \\ Brigham Young University, tracy_nelson@byu.edu \\ Fredrick Michael \\ NASA Marshall Space Flight Center, fredrick.n.michael@nasa.gov \\ Follow this and additional works at: https://scholarsarchive.byu.edu/facpub \\ Part of the Manufacturing Commons
}

\section{Original Publication Citation}

D. Prymak, M. Miles, T. Nelson, and F. Michael, "A High-Pressure Shear Testing Approach to Measure Flow Stresses Near a Friction Stir Welding Tool," Materials Performance and Characterization 10, no. 1 (2021): 727-738. https://doi.org/10.1520/MPC20210049

\section{BYU ScholarsArchive Citation}

Prymak, David; Miles, Michael; Nelson, Tracy W.; and Michael, Fredrick, "A High-Pressure Shear Testing Approach to Measure Flow Stresses Near a Friction Stir Welding Tool" (2021). Faculty Publications. 5567. https://scholarsarchive.byu.edu/facpub/5567

This Peer-Reviewed Article is brought to you for free and open access by BYU ScholarsArchive. It has been accepted for inclusion in Faculty Publications by an authorized administrator of BYU ScholarsArchive. For more information, please contact ellen_amatangelo@byu.edu. 


\section{Materials Performance and Characterization}

David Prymak, ${ }^{1}$ Michael Miles, ${ }^{2}$ Tracy Nelson, ${ }^{1}$ and Fredrick Michael ${ }^{3}$

DOI: 10.1520/MPC20210049

A High-Pressure Shear Testing Approach to Measure Flow Stresses Near a Friction Stir Welding Tool

VOL. 10 / NO. 1 / 2021 
Manuscript received April 29, 2021; accepted for publication August 19, 2021; published online October 15, 2021. Issue published October 15, 2021.

1 Department of Manufacturing Engineering, 265 Crabtree Building, Brigham Young University, Provo, UT 84602, USA

2 Department of Manufacturing Engineering, 265 Crabtree Building, Brigham Young University, Provo, UT 84602, USA (Corresponding author), e-mail: mmiles@byu.edu, (1) https://orcid. org/0000-0003-4558-7629

3 NASA Marshall Space Flight Center, Martin Rd. SW, Huntsville, AL 35808, USA
David Prymak, ${ }^{1}$ Michael Miles, ${ }^{2}$ Tracy Nelson, ${ }^{1}$ and Fredrick Michael ${ }^{3}$

\section{A High-Pressure Shear Testing Approach to Measure Flow Stresses Near a Friction Stir Welding Tool}

\section{Reference}

D. Prymak, M. Miles, T. Nelson, and F. Michael, "A High-Pressure Shear Testing Approach to Measure Flow Stresses Near a Friction Stir Welding Tool," Materials Performance and Characterization 10, no. 1 (2021): 727-738. https://doi.org/10.1520/MPC20210049

\section{ABSTRACT}

A new approach for measuring flow stresses near a spinning friction stir welding (FSW) tool is evaluated on AA 6061-T6 plate. The test consists of plunging a cylindrical tool with a flat face into the plate at different rotational speeds, using a variety of constant vertical loads. A viscosity-based model of the shear layer created under the tool is employed to estimate local flow stresses. The flow stresses measured by this approach exhibited an inverse relationship with temperature and a positive dependence on the pressure imposed by the spinning flat-faced tool. Compared to hot compression and hot torsion results, estimated flow stress levels in high-pressure shear were lower by 20-68 \%, for similar temperatures and strain rates, owing to grain refinement induced by continuous dynamic recrystallization. This high-pressure shear approach could be used to characterize material behavior near a rapidly spinning FSW tool, leading to improved process model predictions.

\section{Keywords}

flow stress measurement, friction stir welding, modeling

\section{Introduction}

Friction stir welding (FSW) has been implemented in a number of industrial sectors over the past two decades, with particular success in the transportation sector. The process has been employed in the fabrication of fast ferries, ships, rail cars, and the automotive industry. FSW has also seen some limited application in aluminum aerospace alloys, where the solid-state nature of FSW eliminates many of the weldability problems associated with fusion welding processes. The ability to produce high-quality welds, with excellent 
post-weld properties, in materials that are traditionally difficult to join has made FSW and its derivatives an attractive potential solution for lightweight aerospace structures.

Development of FSW for use in new alloys or structures is typically accomplished by experimentation to determine tooling design and process parameters that produce sound welds. As a result, broader acceptance and accelerated implementation of FSW in critical applications has been impeded. A robust, high-throughput virtual development capability for tooling design and process parameters determination would aid in removing many of these impediments. At the present time, numerical simulation of FSW is still not predictive enough to avoid significant experimental effort in defining acceptable process parameters that lead to high-quality welds. Improved modeling capabilities that can guide process development and accelerate implementation are needed to enable broader use of this important technology.

Numerical simulations of FSW are challenging, partly because of the large deformations imparted by the welding tool, which spins rapidly and translates at the same time. The motion of the tool creates large gradients in both strain rate and temperature in the material being welded. The Eulerian, Lagrangian, and Arbitrary Lagrangian Eulerian (ALE) formulations have all been utilized for simulation of FSW, and each approach has advantages and limitations. With a Lagrangian approach, the evolution of material flow can be fully captured, but the finite element mesh is deformed along with the material, so frequent remeshing is necessary, practically at each time step, to avoid excessive element distortions. ${ }^{1}$ The Eulerian formulation, within which the computational domain is fixed, avoids remeshing and is consequently more numerically efficient, but the evolution of material flow with time cannot be predicted. The third approach, ALE, is a hybrid in which the mesh is not strictly linked to material flow, but can be adjusted to accommodate high levels of deformation. Each of these modeling frameworks has merit, but the Eulerian one is by far the least intensive from a computation viewpoint and can accommodate more complex tool geometries than the others, making it the choice most often used for development studies.

Regardless of the formulation utilized, capturing the heat generation at the interfaces is the most problematic aspect of modeling FSW. Generally, a friction law is used to model the sliding behavior for the contact interface between the tool and the part. Friction laws that have been used in modeling of FSW include Coulomb, Trescalimited Coulomb, viscoplastic Norton, or Tresca laws. ${ }^{2}$ The friction law is the primary variable that is adjusted to achieve a "best fit" between the desired outcomes of the model relative to a specific set of welding parameters. When welding parameters are changed, the friction law must often be adjusted to achieve a good prediction for the new conditions being modeled. In FSW, heat generated by friction is conducted to the surrounding material, producing thermal softening, which facilitates the bulk upset necessary to produce sound welds. Most models can effectively capture the bulk deformation of material where strains and strain rates are relatively low. This would include the thermo-mechanically affected zone (TMAZ). Flow stresses for accurate bulk deformation predictions can be obtained by hot compression or hot torsion testing. These methods of testing are widely used, where strain rates of 0.0001 to $300 \mathrm{~s}^{-1}$ can be obtained, ${ }^{3}$ although we found compression testing at rates of higher than $30 \mathrm{~s}^{-1}$ to be scarce for aluminum alloys.

Hot torsion does a better job than hot compression of replicating the deformation mode of material near a spinning FSW tool and has been used to create material models for various hot-working processes. The strain levels attainable in hot torsion are greater than those typical of hot compression, but they are still relatively small compared to FSW. ${ }^{4}$ However, the mode of deformation is still not quite comparable to FSW: deformation is not homogenous at smaller strains and most of the deformation occurs at the outer radius of the specimen. Additionally, hot torsion tests are done in the absence of directly applied pressure on the material. In FSW, pressure between the tool and workpiece is substantial and has a beneficial effect on defect formation/size and microstructure formation in the TMAZ and weld nugget. ${ }^{4,5}$

Split Hopkinson Bar testing (SHPB) is a type of compression testing that occurs at very high velocities. Strain rates as low as $300 \mathrm{~s}^{-1}$ and as high as 4,000 s $\mathrm{s}^{-1}$ can be achieved. A striker bar is fired from a gas gun to impact the specimen, with strain gages on the incident and transmitted bars. ${ }^{6}$ Although these tests can be performed at elevated temperatures, the value of the applied strain is very small, often below $0.2{ }^{7}$ FSW produces strains from 
5 to 80 in the weld nugget region; ${ }^{8}$ thus, SHPB is not very applicable in terms of the microstructures produced, which have a strong influence on the measured flow stress.

None of the tests just presented is able to replicate the thermal softening that occurs from continuous dynamic recrystallization (CDRX), as is characteristic of the material sheared by a FSW tool. During hot compression and hot torsion testing, thermal softening occurs primarily from the elevated testing temperature. However, in FSW, both temperature and grain refinement from microstructural evolution (CDRX effect) lead to thermal softening. ${ }^{9}$ For these reasons, a different method of measuring flow stress, in a manner that replicates the deformation mode in FSW, is proposed in this article. The objective of the new test is to more accurately characterize flow stresses at high strain rates, under intense shear deformation, in order to better model the material behavior near the FSW tool, leading to more accurate simulation predictions of the FSW process.

\section{Experimental Procedures and Material Model}

In order to replicate the shear conditions that occur in FSW, a simple tool geometry was used in a plunge configuration, as shown in figure 1. We refer to this as high-pressure shear testing because the material is under a state of pure shear while pressure is applied. The flat, pinless tool is cylindrical in shape and $25 \mathrm{~mm}$ in diameter. The tool was compressed into the top surface of an aluminum plate using vertical loads and rates of rotation that are representative of the FSW process.

The gray-shaded area under the tool in figure 1 represents the layer of material undergoing high levels of shear, which emulates the affect of a rapidly spinning tool. In order to estimate shear stresses in this material, it was modeled as a thin, viscous layer sheared by a spinning disk, as depicted in figure 2.

This material modeling approach follows that presented in Agassant et al. $(1991)^{10}$ where we assume that the thin layer of aluminum under the spinning tool surface can be approximated as a Newtonian material. This approach was chosen in order to model the shearing of the material that occurs during an experiment, which is quite different than fitting curves to data from a tension or compression test, for example. As seen in figure 2, the upper disk is assumed to be rotating at a constant rate $\Omega_{0}$, the distance between the disks is the thickness of the sheared layer $t$, and the velocity gradient between the upper and lower disk is a linear function of both $r$ and $z$ :

$$
v=r \Omega(z)
$$

where the rate of rotation through the thickness depends linearly on $z$ position:

FIG. 1

High-pressure shear geometry used for flow stress measurements. The shaded area under the tool represents a portion of highly sheared aluminum material.

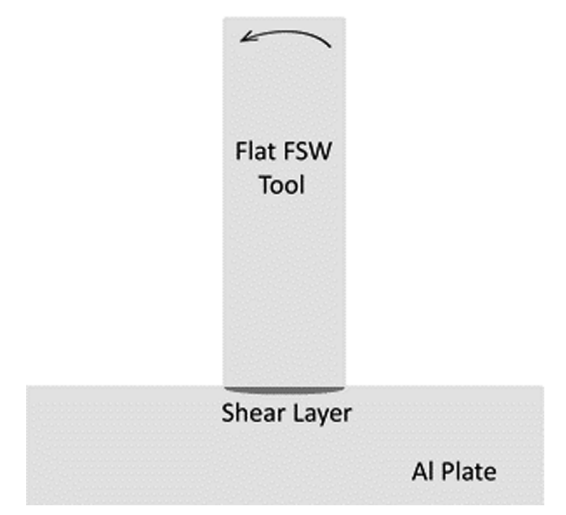


FIG. 2

Upper rotating disk and lower stationary disk shearing a viscous material of thickness $t$, where the upper disk has rotational velocity $\Omega_{\mathrm{O}}$.

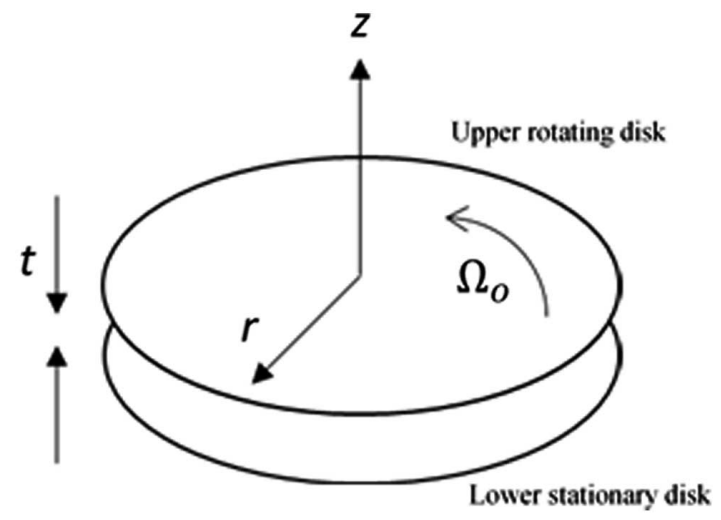

$$
\Omega(z)=\Omega_{0} \frac{z}{t}
$$

The position $z=0$ corresponds to the boundary between the sheared layer and the material underneath that is not sheared (stationary disk), whereas $z=t$ corresponds to the interface where the material contacts the flat tool (rotating disk). It is assumed that there is no slip between the rotating upper disk or the stationary lower disk, which is an approximation, but may be fairly reasonable for aluminum in contact with an $\mathrm{H} 13$ tool surface $(z=t$ position) at high temperature, which is typically from $350^{\circ} \mathrm{C}-500^{\circ} \mathrm{C}$ during FSW. ${ }^{8}$ In the case where some slip occurs between the tool and the workpiece, the estimated strain rate using this method will tend to be an upper bound. Micrographs of the boundary at the $z=0$ position have shown a fairly abrupt transition between fine grains that resulted from dynamic recrystallization and larger grains that were not affected by shear deformation, ${ }^{11}$ as will be seen later.

The shear strain rate in the material is obtained by taking the derivative of the velocity in equation (1) with respect to $z$ :

$$
\dot{\varepsilon}=\frac{\mathrm{dv}}{\mathrm{dz}}=\frac{r \Omega_{0}}{t}
$$

This expression is simplified to the shear rate at the rim of the disk:

$$
\dot{\varepsilon}=R \Omega_{0} / t
$$

as is done in analogous modeling of a disk rheometer. ${ }^{12}$

Then, the shear stress in the material, or flow stress, is a function of strain rate and viscosity $\mu$ (Newtonian assumption):

$$
\tau=\mu \dot{\varepsilon}
$$

The torque required to rotate the disk is obtained by integrating the product of radial distance from the axis of rotation and the shear stress over the surface of the disk:

$$
T=\int_{0}^{R} r \mu \frac{r \Omega_{0}}{t} 2 \pi r \mathrm{~d} r=\frac{\pi \mu \Omega_{0} R^{4}}{2 t}
$$

where $R$ is taken as the radius of the sheared zone, which is approximately the radius of the tool. 
Because the torque is a parameter that can be measured during a plunge experiment, it becomes an input that allows for computing the viscosity of the material:

$$
\mu=\frac{2 t T}{\pi \Omega_{0} R^{4}}
$$

The strain rate computed from equation (4) and viscosity from equation (7) are combined to estimate shear flow stress, using equation (5).

The experiments for estimating shear flow stresses under the tool were performed on 12-mm-thick AA6061T6 plates, with several different rpm and vertical loads. The nominal composition for AA6061-T6 is magnesium $0.8-1.2$, silicon $0.4-0.8$, copper $0.15-0.4$, iron $0-0.7$, chromium $0.04-0.35$, zinc $0-0.25$, and titanium $0-0.15$ (in wt. $\%)$ and the tensile properties are shown in Table 1.

Plunge tests were sensitive to rotational speed. If the rpm was too low, for a given vertical load, the material would not flow, as shown in figure $3 A$ and $3 B$.

Therefore, parameters were chosen based on an ability to generate smooth flow of material under the tool. The output of the experiments consisted of torque from the machine spindle, $T$, and thickness of the shear layer $t$ created by the spinning tool. This allowed for estimating the strain rate and shear stress in the material from equations (4) and (5). Some examples of plates that were plunged over different time periods are shown in figure 4.

A summary of the final parameters used for the high-pressure shear experiments is provided below in Table 2.

The depth of the plunge was not controlled; only the vertical load and test duration were controlled, which resulted in different shear layer thicknesses. The thickness of the shear layer under the tool was measured from cross sections (as seen in fig. 4). The layers were measured from the top surface of the weld to a depth that corresponds to the boundary between material that was sheared and material that was not. This boundary was determined visually from the macrographs, as shown in figure 5, including magnified observation of the boundary region in order to ensure accuracy.

TABLE 1

Tensile properties of AA 6061-T6

\begin{tabular}{lcc}
\hline Yield Strength, MPa & Ultimate Tensile Strength, MPa & Total Elongation, \% \\
\hline 276 & 310 & 17 \\
\hline
\end{tabular}

FIG. 3 Top views of preliminary plunge experiments with vertical load of $27 \mathrm{kN}$ and tool rotational speeds of $(A) 100 \mathrm{rpm}$, (B) $200 \mathrm{rpm},(C) 400 \mathrm{rpm}$, and (D) $600 \mathrm{rpm}$.

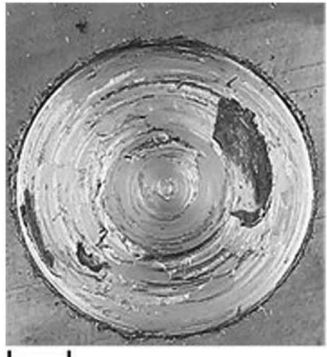

$\longmapsto \quad(A)$

$5 \mathrm{~mm}$

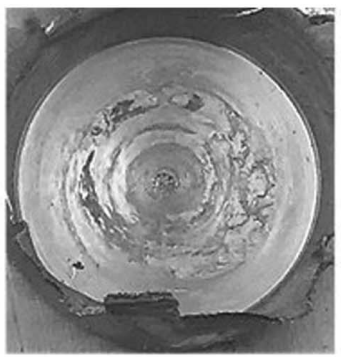

(B)

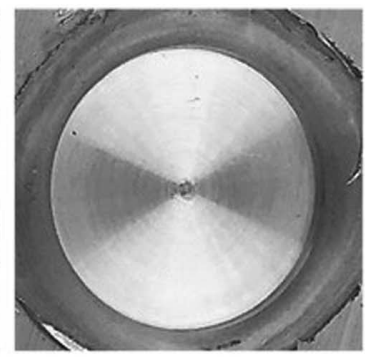

$(C)$

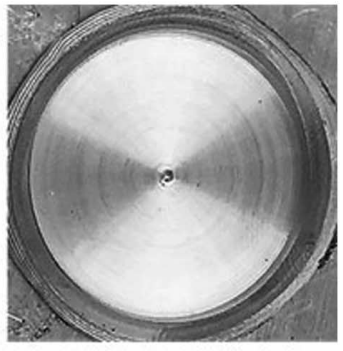

$(D)$ 
FIG. 4 Top view of plates for four different experiments, using a tool speed of $400 \mathrm{rpm}$ and a constant vertical load of $27 \mathrm{kN}$. The test was run for $(A) 5 \mathrm{~s},(B) 15 \mathrm{~s},(C) 25 \mathrm{~s}$, and (D) $35 \mathrm{~s}$. Cross sections showing shear layer thickness are below each top view. Measured thicknesses were $(A) 0.9 \mathrm{~mm},(B) 2.6 \mathrm{~mm},(C) 2.7 \mathrm{~mm}$, and (D) $3.5 \mathrm{~mm}$.

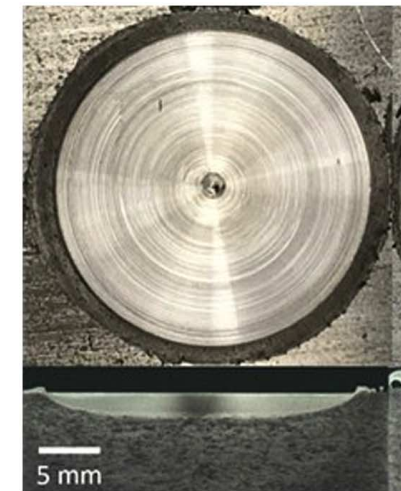

(A)

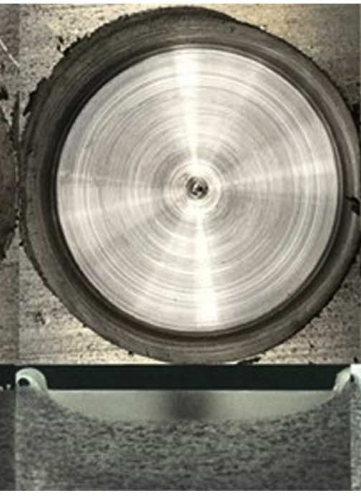

(B)

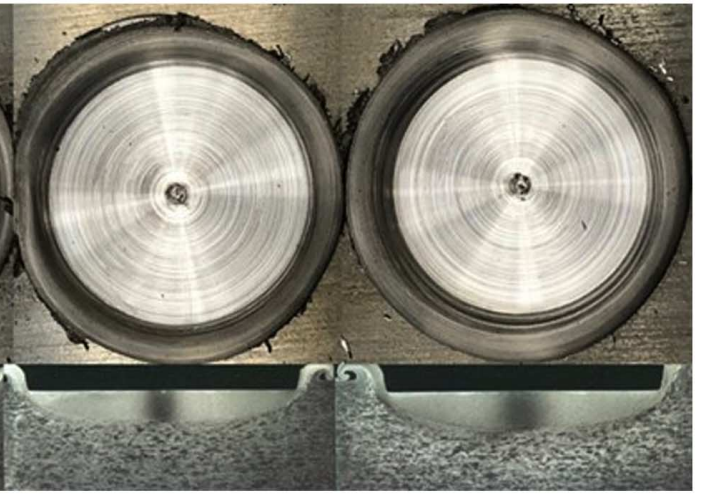

$(C)$

$(D)$

TABLE 2

Parameters used for high-pressure shear experiments

\begin{tabular}{lcc}
\hline Vertical Load, kN & RPM & Duration of Test, s \\
\hline 18 & 400 & $10,20,30,40$ \\
27 & 400 & $5,15,25,35$ \\
36 & 400 & $2.5,5,10,15$ \\
\hline
\end{tabular}

FIG. 5 Macrograph of shear layer (left) and magnified image (right) of the boundary between the shear layer and the undeformed material underneath.
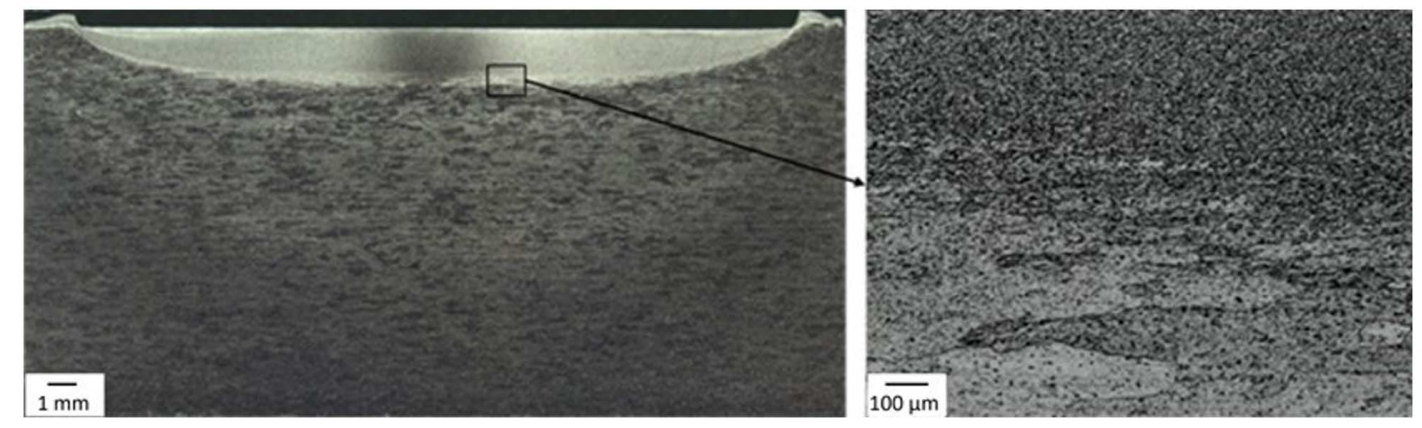

As can be seen in the magnified image of figure 5, the grain size in the sheared material is much smaller than grains in the area below it. The small grains are a result of dynamic recrystallization that is promoted by high levels of shear deformation at high temperatures.

Temperatures in the tool were measured during the high-pressure shear experiments with a thermocouple, embedded at a point $11 \mathrm{~mm}$ from the center of the tool and $1 \mathrm{~mm}$ from the face of the tool, as shown in figure 6 .

The tool temperature was measured during each experiment and plotted, along with estimated shear stress under the tool, as a function of test parameters. The experiments were performed using a constant tool speed of $400 \mathrm{rpm}$, where vertical loads of 18, 27, and $36 \mathrm{kN}$ were imposed using the load control capability of the machine. 
FIG. 6

Thermocouple position in the tool used for highpressure shear experiments.

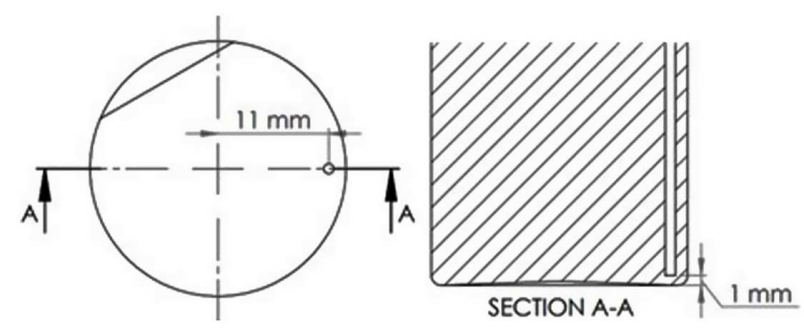

For each set of parameters, different plunge durations allowed for studying the effect of time and temperature and flow stresses.

\section{Results and Discussion}

A representative curve of shear stress in the layer of material under the tool, along with tool temperature as measured by thermocouple (location in fig. 6), is shown in figure 7.

The shear stress in figure 7 peaks early in the plunge and then drops as the temperature increases. For FSW at a travel speed of $100 \mathrm{~mm} / \mathrm{min}$ (which is considered slow), the length of time for the width of a 6-mm-diameter pin to pass a given location is just under $4 \mathrm{~s}$. Therefore, it is reasonable that the flow stresses characteristic of FSW would be somewhere just after the peak in figure 7, e.g., maybe in the interval between 4 and 5 s. Nevertheless, flow stresses were measured at several time increments along the entire curve, over a range of strain rates and temperatures for each set of parameters. As such, the letters a- $d$ in figure 7 are provided as a reference to the durations of different high-pressure shear experiments. Though one complete curve is shown in figure 7 ,

FIG. 7 Shear stress and tool temperature as a function of time for high-pressure shear experiments at 400 rpm at a constant vertical load of $27 \mathrm{kN}$.

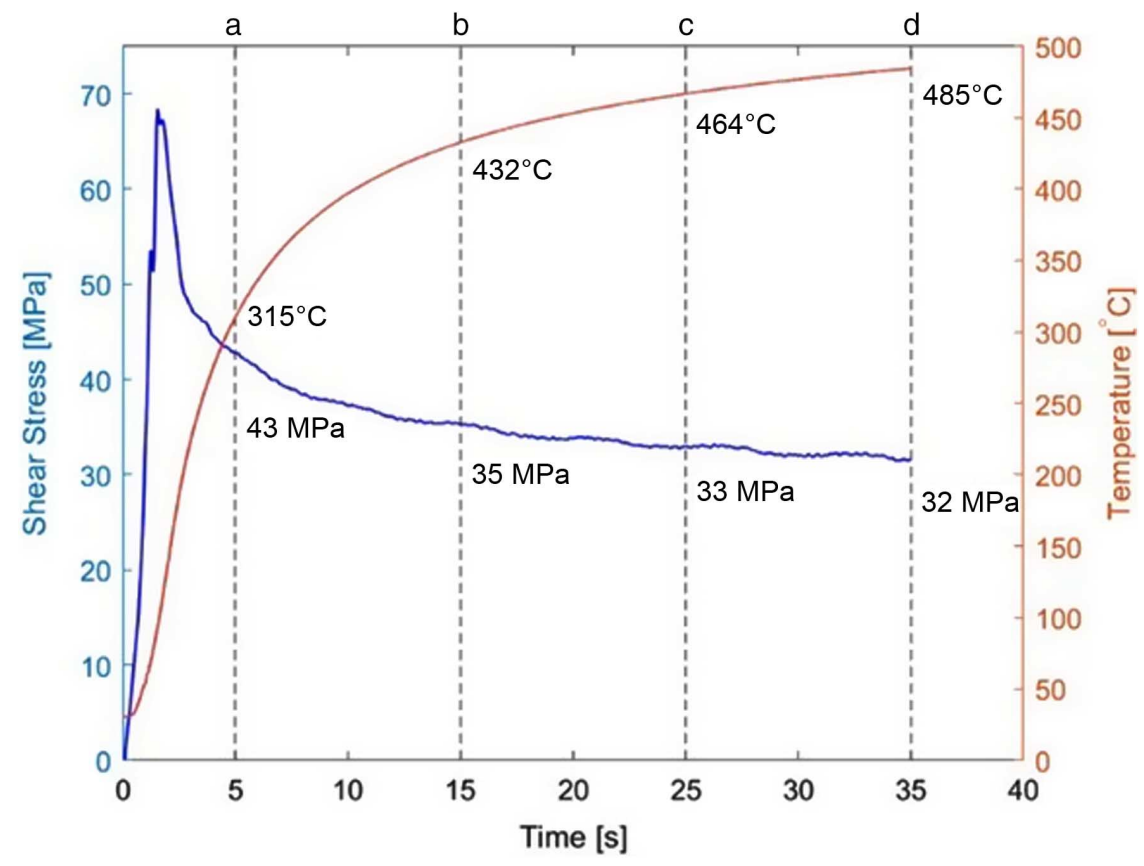


individual experiments were performed in order to terminate the deformation and thermal cycle so the depth of the material deformation below the tool could be measured.

Table 3 presents the data from all high-pressure shear experiments performed at $400 \mathrm{rpm}$. Shear flow stresses varied from 27-51 MPa over a range of strain rate and tool temperatures of $149-792 \mathrm{~s}^{-1}$ and $197^{\circ} \mathrm{C}-485^{\circ} \mathrm{C}$, respectively.

The temperature and strain rate data are plotted in figure $8 A$ and $8 B$, where they appear to reach steadystate after about $10 \mathrm{~s}$. The saturation in temperature indicates an equilibrium in the rate of heat removal versus the rate of heat generation. At the same time, the strain rate saturates as the growth in the thickness of the shear layer tapers off with time (average strain rate is a function of layer thickness, per equations (3)-(5)).

A strong inverse relationship between shear flow stress and temperature is shown in figure 9, as would be expected.

Finally, the measured shear flow stresses display a clear dependence on the pressure (as calculated from the applied z-force divided by the area of the tool) exerted by the tool, for different constant loads applied during the test. Figure 10 shows an increasing shear flow stress with applied pressure, where the spread of values at each pressure reflects the effect of temperature (lower temperatures equate to higher flow stresses at each pressure).

Although the effect of pressure has not been explicitly included in most material models used for simulation of FSW, these experimental data indicate the need to account for such a dependence. Hot torsion testing does not impose a pressure on the material. Hot compression results in a very heterogenous stress state in the material,

TABLE 3

Flow stresses as a function of strain rate and temperature, for AA 6061-T6

\begin{tabular}{|c|c|c|c|c|c|}
\hline Load, kN & Duration, s & Torque, $\mathrm{N}-\mathrm{m}$ & Flow Stress, $\mathrm{MPa}$ & Temperature, ${ }^{\circ} \mathrm{C}$ & Strain Rate, $\mathrm{s}^{-1}$ \\
\hline 18 & 10 & 112 & 35 & 368 & 279 \\
\hline 18 & 20 & 95 & 30 & 429 & 236 \\
\hline 18 & 30 & 89 & 29 & 452 & 214 \\
\hline 18 & 40 & 87 & 27 & 464 & 209 \\
\hline 27 & 5 & 134 & 43 & 315 & 599 \\
\hline 27 & 15 & 111 & 35 & 432 & 208 \\
\hline 27 & 25 & 105 & 33 & 464 & 195 \\
\hline 27 & 35 & 99 & 32 & 485 & 149 \\
\hline 36 & 2.5 & 166 & 51 & 197 & 792 \\
\hline 36 & 5 & 150 & 47 & 321 & 553 \\
\hline 36 & 10 & 132 & 42 & 413 & 184 \\
\hline 36 & 15 & 126 & 40 & 455 & 164 \\
\hline
\end{tabular}

FIG. 8 Inverse relationship between $(A)$ temperature and $(B)$ strain rate, as a function of plunge dwell time.

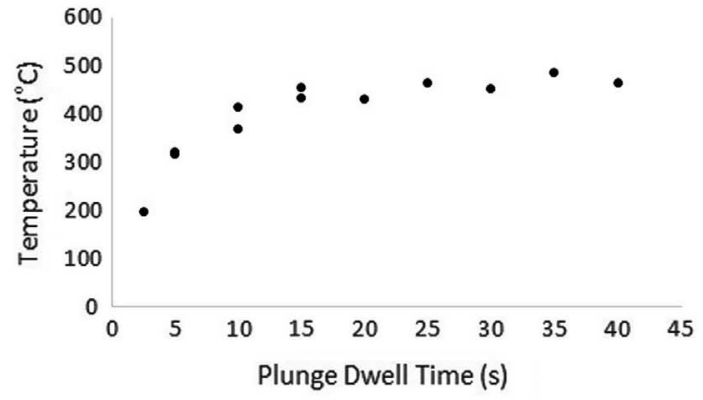

(A)

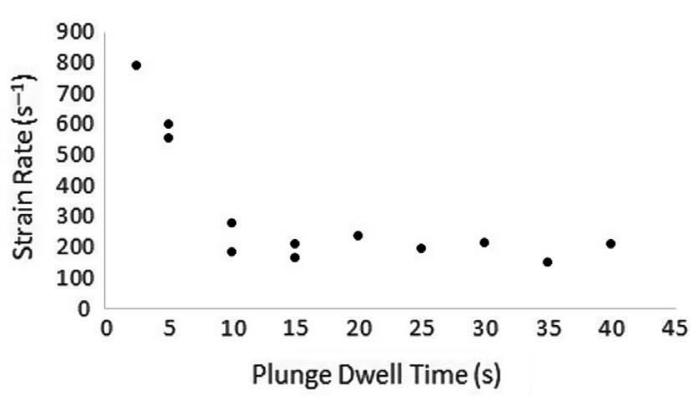

(B) 
FIG. 9

Inverse relationship between shear flow stress and temperature.

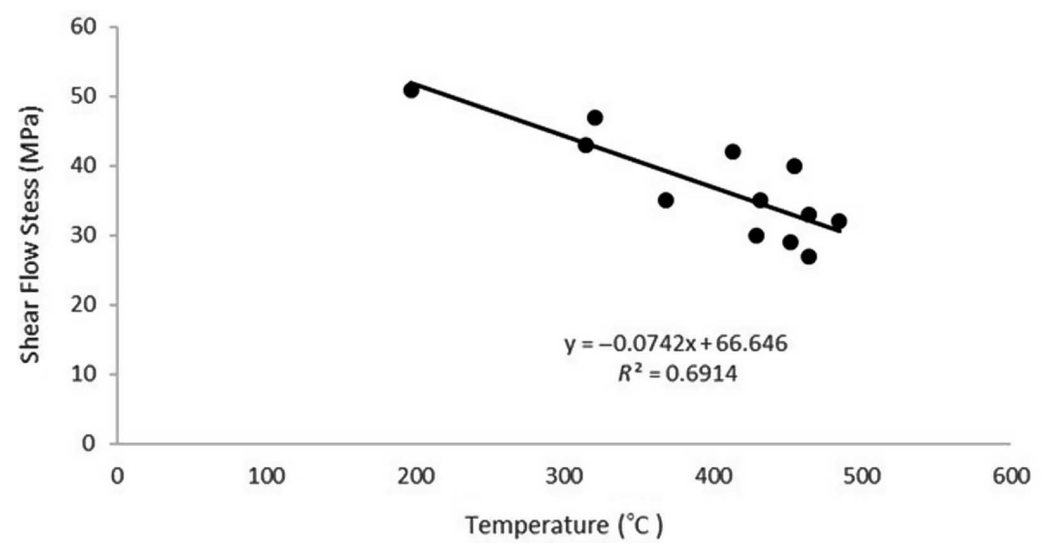

FIG. 10

Positive relationship between measured shear flow stress and pressure exerted by the tool. The range of flow stresses at each pressure is caused by different test temperatures, where lower temperatures result in greater levels of flow stress.

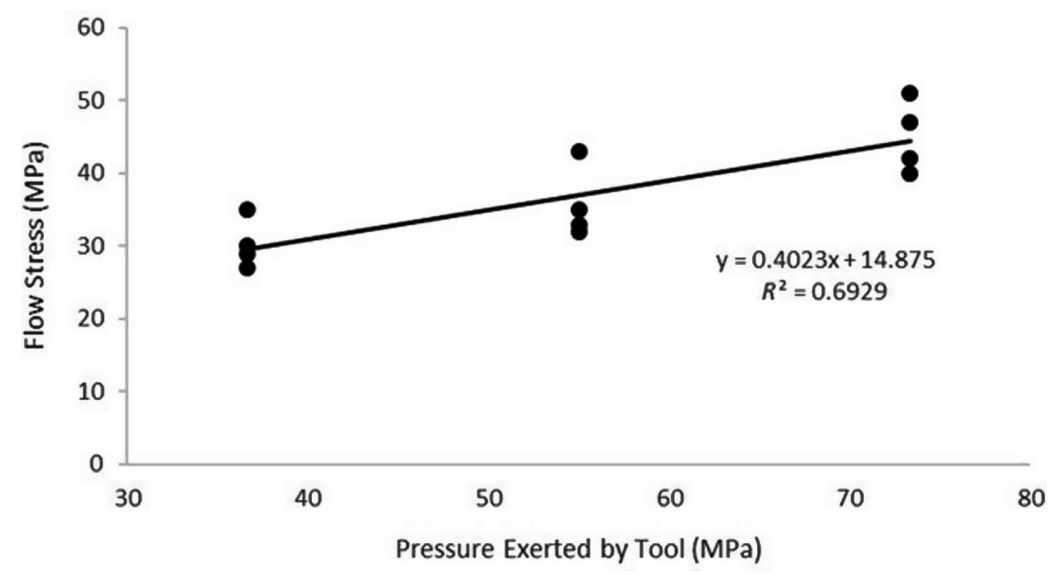

owing to shear layers along the diagonals of the specimen that cannot be avoided, even when the specimen ends are well-lubricated. The pressure dependency seen in the current data aligns with the FSW process because parameters that result in good, consolidated welds always exert sufficient pressure on the material being stirred, in order to avoid tunnel defects or voids.

The shear flow stress data in Table 1 are compared with hot compression and hot torsion data from the literature, ${ }^{13,14}$ as presented in figure 11. For a given temperature (indicated by color on the graphs), the highpressure shear experiments generate flow stresses that are 20-68 \% lower than those measured by hot compression or hot torsion.

The range of flow stresses generated from the experiments in the current work are fairly narrow, because parameters that were able to achieve stable flow in the material under the tool resulted in relatively high strain rates and temperatures. But even for experiments where temperatures were lower, in the range of $200^{\circ} \mathrm{C}-300^{\circ} \mathrm{C}$, the estimated flow stresses from high-pressure shear testing were much lower than those from hot compression or hot torsion, as seen in figure 11 (i.e., about $51 \mathrm{MPa}$ for high-pressure shear with tool temperature of $197^{\circ} \mathrm{C}$ and closer to $160 \mathrm{MPa}$ for hot torsion, between $200^{\circ} \mathrm{C}$ and $250^{\circ} \mathrm{C}$ ).

As we have previously discussed, the mode of deformation imposed during testing is important in order to replicate the conditions inherent in FSW. The material in contact with the surfaces of the shoulder and pin of an 
FIG. 11 Flow stresses measured by high-pressure shear experiments, compared to data from $(A)$ hot compression ${ }^{13}$ and (B) hot torsion experiments. ${ }^{14}$

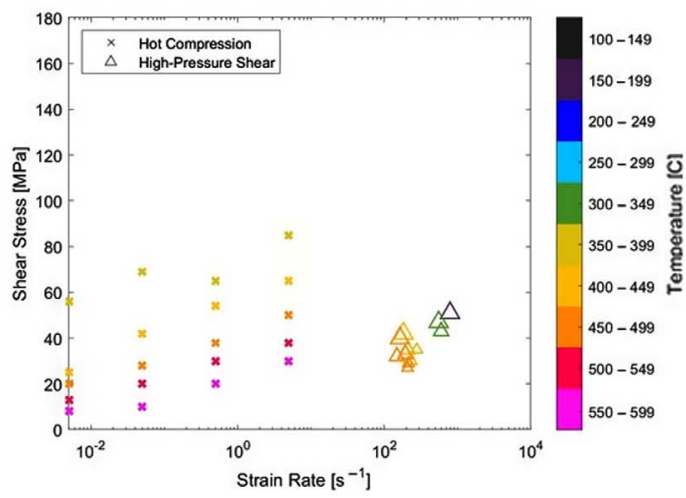

(A)

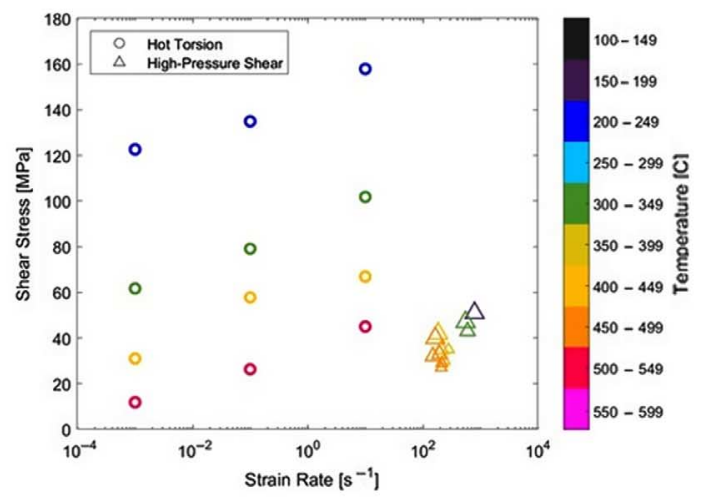

(B)

FSW tool are essentially in pure shear while under significant pressure. Therefore, the use of hot compression or hot torsion data in constitutive material behavior for modeling these high shear regions in FSW may not be accurate enough to enable predictive simulation results.

The comparisons in figure 11 can be explained by the role that microstructure and recovery processes play in local flow stresses. As presented in the literature section of this article, CDRX is well documented as a recovery mechanism in FSW of aluminum alloys. Additionally, prior work in FSW/friction stir processing ${ }^{15-18}$ has demonstrated that the grain sizes near the tool were submicron, and even in the range of tens of nanometers.

The relationship between flow stress and grain size has been established in prior work in AA 7075, where lower flow stresses in compression were measured in specimens with smaller grain sizes for the same temperatures and strain rates. ${ }^{19}$ It was postulated that smaller grains facilitated a grain boundary sliding deformation mechanism at the temperatures imposed during the testing. This relationship is likely contributing to the low flow stresses observed in the present study, with the relatively high temperatures and shear deformation mode promoting CDRX recovery and grain boundary sliding in the shear layer under the tool.

Given the high level of shear generated under the flat tool, a more valid comparison of yield stress (or flow stress) measured in hot compression could be achieved by converting the uniaxial compression flow stress to an equivalent pure shear flow stress, using the von Mises criterion:

$$
\tau=\sigma_{0} / \sqrt{3}
$$

where $\tau$ is the yield stress in pure shear and $\sigma_{0}$ is the yield stress in uniaxial compression (or tension). Certainly, if hot compression flow stresses were converted to the pure shear equivalent using equation (8), many of the values provided in the literature would be more appropriate for modeling local flow stresses in the high-shear region near the surface of a FSW tool. However, merely converting hot compression flow stress to an equivalent pure shear value would be insufficient, as this does not fully capture the effect of microstructural evolution on flow stresses occurring near the spinning FSW tool. Prior work in FSW has documented the effect of CDRX on grain size. ${ }^{20}$ For this reason, the relatively simple flat tool configuration of the high-pressure shear test, coupled with the viscous material model presented in equations (1)-(7), appears to be a reasonable method for measuring local flow stresses near the surface of an FSW tool. This new approach could be used to better calibrate constitutive models, like Johnson-Cook, for simulating the high strain rates and temperatures experienced in FSW. ${ }^{8}$ Though the test does not provide flow stress as a function of strain, since this would not have much meaning for material being sheared continuously by a rapidly rotating tool, it does provide a flow stress at a given strain rate and 
temperature, which is a useful data point, as most flow stress curves are relatively flat as a function of strain for the high temperatures that occur during FSW. The test also shows that the flow stress is dependent on pressure, which is not usually included in constitutive laws, but could be in future efforts, in order to better model the material behavior under FSW conditions. Hot compression and/or hot torsion data are still useful for characterizing material behavior further from the tool, where strain rates and temperatures are lower, and where the material is not under intense shear deformation.

\section{Conclusions}

A new high-pressure shear test for measuring flow stresses at the elevated strain rates and temperatures present in the stir zone during FSW is proposed. A simple flat tool is plunged into the material of interest at different levels of rotational speed and vertical load while torques and temperatures are measured. A viscous material model for the shear layer under the rotating tool uses a Newtonian material assumption, where viscosity is calculated as a function of torque, shear layer thickness, and rotational tool speed. The following conclusions were drawn from the results presented in this article:

1. High-pressure shear experiments with the flat tool in AA 6061-T6 plate, and the resulting shear flow stresses estimated from the analytical model, were found to be from 20 to $68 \%$ lower than those found in the literature at similar temperatures for hot compression and hot torsion of the same alloy. Strain rates for the hot compression and hot torsion tests were lower than those of the high-pressure shear experiments, so the differences would likely be even greater had the strain rates been equal.

2. The high-pressure shear experiments exhibited a saturation of the tool temperature after about $10 \mathrm{~s}$ of plunge duration, and a corresponding drop and saturation in strain rate in the shear layer at about the same point in time. Correlated to these observations was the evolution of shear layer thickness under the tool, which increased until the plunge duration reached about $10 \mathrm{~s}$, then stabilized and remained relatively constant beyond it.

3. Measured shear flow stresses exhibited a dependence on pressure exerted by the tool, where greater applied pressures equated to greater levels of flow stress. This replicates the conditions created in the stir zone in FSW, where sufficient pressure is needed to avoid tunnel defects or voids.

4. The intense shear deformation occurring under the flat tool in the high-pressure shear experiments emulates the conditions of FSW, including microstructure evolution and grain refinement, resulting in relatively low flow stresses compared to those measured by hot compression or hot torsion. Prior work has documented the relationship between smaller grain sizes and decreased flow stresses during high temperature deformation in AA 7075. Thus, the observation of relatively low flow stresses measured in the present work are understood in the context of test conditions that promote CDRX recovery and a grain boundary sliding deformation mechanism.

The current approach could be used to improve the accuracy of FSW models by providing more accurate flow stresses for the material layer sheared by the spinning tool in order to better calibrate constitutive laws, like Johnson-Cook. At the same time, deformation occurring farther from the FSW tool, where the shear deformation is less intense, could be reasonably characterized using flow stresses from hot compression or hot torsion testing.

\section{ACKNOWLEDGMENTS}

This work was supported by NASA Early Stage Innovations (ESI) grant 80NSSC19K022.

\section{References}

1. G. Buffa, J. Hua, R. Shivpuri, and L. Fratini, "A Continuum Based FEM Model for Friction Stir Welding-Model Development," Materials Science and Engineering: A 419, no. 1 (March 2006): 389-396, https://doi.org/10.1016/j. msea.2005.09.040 
2. M. Assidi, L. Fourment, S. Guerdoux, and T. W. Nelson, "Friction Model for Friction Stir Welding Process Simulation: Calibrations from Welding Experiments," International Journal of Machine Tools \& Manufacture 50, no. 2 (February 2010): 143-155, https://doi.org/10.1016/j.ijmachtools.2009.11.008

3. C. M. Sellars and W. J. M. Tegart, "Hot Workability," International Metallurgical Reviews 17, no. 1 (1972): 1-24, https:// doi.org/10.1179/imtlr.1972.17.1.1

4. J. R. Rule and J. C. Lippold, "Physical Simulation of Friction Stir Welding and Processing of Nickel-Base Alloys Using Hot Torsion," Metallurgical and Materials Transactions A 44, no. 8 (2013): 3649-3663.

5. Y. G. Kim, H. Fujii, T. Tsumura, T. Komazaki, and K. Nakata, "Three Defect Types in Friction Stir Welding of Aluminum Die Casting Alloy," Materials Science and Engineering: A 415, no. 1 (January 2006): 250-254, https://doi.org/10.1016/j. msea.2005.09.072

6. A. Gilat and Y. H. Pao, "High-Rate Decremental-Strain-Rate Test," Experimental Mechanics 28, no. 3 (September 1988): 322-325.

7. K. E. Tello, A. P. Gerlich, and P. F. Mendez, "Constants for Hot Deformation Constitutive Models for Recent Experimental Data," Science and Technology of Welding and Joining 15, no. 3 (2010): 260-266, https://doi.org/10. 1179/136217110X12665778348380

8. K. Kuykendall, T. Nelson, and C. Sorensen, "On the Selection of Constitutive Laws Used in Modeling Friction Stir Welding," International Journal of Machine Tools and Manufacture 74 (2013): 74-85, https://doi.org/10.1016/j. ijmachtools.2013.07.004

9. A. Manes, L. Peroni, M. Scapin, and M. Giglio, "Analysis of Strain Rate Behavior of an Al 6061 T6 Alloy," Procedia Engineering 10 (2011): 3477-3482, https://doi.org/10.1016/j.proeng.2011.04.573

10. J.-F. Agassant, P. Avenas, P. J. Carreau, B. Vergenes, and M. Vincent, Polymer Processing: Principles and Modeling (New York: Hanser Publications, 1991).

11. P. M. G. P. Moreira, T. Santos, S. M. O. Tavares, V. Richter-Trummer, P. Vilaca, and P. M. S. T. de Castro, "Mechanical and Metallurgical Characterization of Friction Stir Welding Joints of AA6061-T6 with AA6082-T6," Materials \& Design 30, no. 1 (January 2009): 180-187, https://doi.org/10.1016/j.matdes.2008.04.042

12. H. P. Kavehpour and G. H. McKinley, "Tribo-rheometry from Gap-Dependent Rheology to Tribology," Tribology Letters 17, no. 2 (August 2004): 327-335, https://doi.org/10.1023/B:TRIL.0000032471.06795.ea

13. H. Zhang, L. Li, D. Yuan, and D. Peng, "Hot Deformation Behavior of the New Al-Mg-Si-Cu Aluminum Alloy during Compression at Elevated Temperatures," Materials Characterization 58, no. 2 (2007): 168-173.

14. S. Spigarelli, E. Evangelista, and H. J. McQueen, "Study of Hot Workability of a Heat Treated AA6082 Aluminum Alloy," Scripta Materialia 49, no. 2 (July 2003): 179-183, https://doi.org/10.1016/S1359-6462(03)00206-9

15. T. L. Giles, K. Oh-Ishi, A. P. Zhilyaev, S. Swaminathan, M. W. Mahoney, and T. R. Mcnelley, "The Effect of Friction Stir Processing on the Microstructure and Mechanical Properties of an Aluminum Lithium Alloy," Metallurgical and Materials Transactions A 40, no. 1 (November 2009): 104-115, https://doi.org/10.1007/s11661-008-9698-8

16. K. Oh-Ishi, A. P. Zhilyaev, and T. R. McNelley, "A Microtexture Investigation of Recrystallization during Friction Stir Processing of As-Cast NiAl Bronze,” Metallurgical and Materials Transactions A 37, no. 7 (July 2006): 2239-2251.

17. J.-Q. Su, T. W. Nelson, T. R. Mcnelley, and R. S. Mishra, "Development of Nanocrystalline Structure in Cu during Friction Stir Processing (FSP)," Materials Science and Engineering A 528, no. 16 (June 2011): 5458-5464, https://doi.org/10.1016/j. msea.2011.03.043

18. J.-Q. Su, T. W. Nelson, and C. J. Sterling, "Friction Stir Processing of Large-Area Bulk UFG Aluminum Alloys," Scripta Materialia 52, no. 2 (January 2005): 135-140, https://doi.org/10.1016/j.scriptamat.2004.09.014

19. Y. Yang, Z. Zhang, X. Li, Q. Wang, and Y. Zhang, "The Effects of Grain Size on the Hot Deformation and Processing Map for 7075 Aluminum Alloy," Materials \& Design 51 (October 2013): 592-597, https://doi.org/10.1016/j.matdes.2013.04. 034

20. T. R. McNelley, S. Swaminathan, and J. Q. Su, "Recrystallization Mechanisms during Friction Stir Welding/Processing of Aluminum Alloys,” Scripta Materialia 58, no. 5 (March 2008): 349-354, https://doi.org/10.1016/j.scriptamat.2007.09.064 